\title{
Polycrystalline Silicon Characteristics Dependence on Starting Amorphous Material
}

\author{
T. Mohammed-Brahim, M. Sarret, D. Briand, K. Kis-Sion, O. Bonnaud and A. Hadjaj* \\ Groupe de Microélectronique et Visualisation, URA 1648 du CNRS, Université de Rennes I, Campus de \\ Beaulieu, Bât. 11B, 35042 Rennes cedex, France \\ * L.P.I.C.M., Ecole Polytechnique, 91120 Palaiseau, France
}

\begin{abstract}
Silicon films, typically 1 um thick, are deposited by low pressure chemical vapor deposition using pure silane at $550^{\circ} \mathrm{C}$ and 3 deposition rates : 13,23 and $45 \AA / \mathrm{mn}$. Using numerous physical, optical and electrical characterization techniques, we show an evident amorphous character of these as-deposited films. Films deposited at high rate correspond more likely to the relaxed amorphous network. The quality of the polysilicon produced by annealing these high deposition rate films at $600^{\circ} \mathrm{C}$ is largely enhanced. The crystallization time, defined from the in-situ conductivity measurements at $600^{\circ} \mathrm{C}$, is about $4 \mathrm{~h}$ for the high deposition rate amorphous film. Such time is very attractive in the attempt to obtain simultaneously "acceptable " crystallization time and high quality polysilicon. This assertion is emphasized if we consider the total time $t$ of the process (deposition time and crystallization time).
\end{abstract}

\section{INTRODUCTION}

Since the end of the 80 's, polycristalline silicon (polysilicon) is extensively studied for the application in active matrix liquid crystal displays [1]. On the other hand, polysilicon may be attractive as a material in the photovoltaic conversion of the solar energy. These major applications both need a low temperature glass substrate $\left(\leq 600^{\circ} \mathrm{C}\right)$ and high quality polysilicon. This last requirement is not evident, particularly in solar cells applications where 20 to $30 \mu \mathrm{m}$ thick films are needed.

Good quality polysilicon films can be obtained by the deposition of amorphous silicon and subsequent crystallization [2]. The purpose of this process is to suppress the spontaneous crystallization and to control the number of nuclei. It is realized by reduction of the deposition and annealing temperatures in plasma enhanced chemical vapor deposition (PECVD) technique [3], low pressure chemical vapor deposition (LPCVD) technique using silane [4,5] and others high silanes, $\mathrm{Si}_{2} \mathrm{H}_{6}$ particularly [6]. The too long crystallization time of these amorphous deposited films constitutes however a drawback for practical use. Attempts were given to increase the crystallization time by deposition of crystallized mixed-phase films [7] or double layer (doped and undoped) film [8].

The present study checks the possibility to obtain simultaneously acceptable crystallization time and high quality polysilicon using the known LPCVD with silane technique. This is may be done by a control of the quality of the amorphous film and then the nucleation time.

Indeed, amorphous material terminology is commonly used for a wide range of different microstructural disordred materials.

The microstructure of the amorphous starting material depends on the deposition technique : PECVD [9], Thermal CVD ( LPCVD or atmospheric pressure CVD [10] ), radio frequency (RF) or direct current (DC) sputtering [11-13] and on the deposition parameters [14,15]. This great number of different amorphous materials leads to a wide range of crystallization modes and consequently of polycristalline silicon 
materials. For example, it was shown that the nucleation process is different in LPCVD and APCVD amorphous deposited silicon [16].

The main purpose of this contribution is to investigate the amorphous silicon film deposited by LPCVD using pure silane at $550^{\circ} \mathrm{C}$ and its crystallization at $600^{\circ} \mathrm{C}$ as a function of the deposition rate or pressure. The characterization techniques used conductance-annealing time at constant temperature, conductancetemperature, optical transmission in visible and near infrared range (NIR) and ellypsometry in ultraviolet and visible ranges (UV-VIS) and $\mathrm{X}$ ray diffraction using a long count time (many hours) for each line.

\section{EXPERIMENTAL DETAILS}

Silicon films, typically $1 \mu \mathrm{m}$ thick, are deposited in a conventional horizontal hot-wall LPCVD reactor using pure silane as source gas. The substrates used were $5 \times 5 \mathrm{~cm}^{2}$ Corning 7059 glass platets. The deposition conditions were fixed at a silane flow rate of 50 standard cubic centimeters sccm, a temperature of $550^{\circ} \mathrm{C}$, and pressures of 10,30 and $100 \mathrm{~Pa}$. The depositon rates under these conditions were 13,23 and

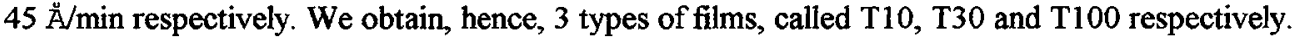

Starting from these deposited films, different samples are annealed at $600^{\circ} \mathrm{C}$ under a vacuum better than $3.10^{-5} \mathrm{~Pa}$ for $1,2,3,6,12$ and $24 \mathrm{~h}$. The samples are labelled type of film - annealing time ( e.g. T10-1, T10-2,..). The as-deposited films are numbered T10-0, T30-0 and T100-0.

The thicknesses are determined by Talystep measurements and confirmed by optical transmission and ellipsometry techniques. These two last techniques, $\mathrm{X}$-ray diffraction and conductance measurements are used to characterize the different samples.

Before these characterizations, the solid-phase crystallisation of the as-deposited samples during isothermal annealing at $600^{\circ} \mathrm{C}$ under vacuum was studied by in-situ monitoring the film conductance. To this purpose, platinum coplanar electrodes are electron beam eyaporated.

For conductance measurements between 120 and $620 \mathrm{~K}$, aluminium coplanar electrodes ( length $1.6 \mathrm{~cm}$, separation $1.2 \mathrm{~cm}$ ) were evaporated. The films were placed on a copper block under vacuum of $10^{-6}$ Torr. The temperature was varied using a direct heating and/or a contact with liquid nitrogen. It was controlled by means of a platinum resistor fixed close near the sample. Before any measurements, the films were annealed at a residual pressure of $0.1 \mathrm{mPa}$ and temperature of $620 \mathrm{~K}$. The purpose of this annealing is an outgassing of the film.

The optical transmission was measured with a double grating spectrophotometer (CARY 5) between 0.35 and $2.5 \mu \mathrm{m}$. Using the usual procedure [17] the film thickness, the refractive index and the absorption coefficient were deduced.

The UV-VIS spectroscopic ellipsometry ( UVISEL ISA-Jobin Yvon) measurements were performed in the 1.7-5 eV energy range. Ellipsometry allows to obtain in a semi-infinite medium model, the pseudodielectric function $\langle\varepsilon\rangle=\left\langle\varepsilon_{1}\right\rangle+\mathrm{i}\left\langle\varepsilon_{2}\right\rangle$. The morphology (density and surface roughness) and structure (amorphous, cristalline, mixed phase) of the films were characterized by the evolution of $\left\langle\varepsilon_{2}\right\rangle$ and computed through the use of the Bruggeman effective medium approximation (BEMA).

When using X-ray diffraction to characterize the structure of the material, the major works on polycristalline silicon determine the crystal size from the full width at half maxima (FWHM) of the lines utilizing the known Scherrer formula.

Using hypothesis on the line shapes and data treatments of the different order lines, more informations may be deduced however from X-ray diffraction patterns [18]. Line shapes and line broadening are, as known, influenced by the dimensions of the coherently diffracting domains (crystallite-size effects) but also by the microstructural features as the variation in interatomic distances due to internal stresses, micro-twining, dislocations and other forms of atomic disorder.

\begin{tabular}{|c|c|c|c|c|}
\hline line & $\begin{array}{c}\text { Maximum } \\
2 \theta\end{array}$ & $\begin{array}{c}\text { Scanned } \\
\text { Range (20) }\end{array}$ & $\begin{array}{c}\text { Counting } \\
\text { Time (s) }\end{array}$ & $\begin{array}{c}\text { Scanning } \\
\text { Time }\end{array}$ \\
\hline 111 & 28.44 & $26.50-30.00$ & 20 & 1h $57 \mathrm{~min}$ \\
\hline 220 & 47.349 & $46.30-48.40$ & 40 & 2h 20min \\
\hline 311 & 56.171 & $55.00-57.20$ & 40 & 2h 27min \\
\hline
\end{tabular}

Table I: Scanning conditions of the diffraction patterns 
In this work $\mathrm{X}$-ray diffraction data were collected with a Siemens D500 high resolution powder diffractometer using monochromatic $\mathrm{CuK} \alpha_{1} \mathrm{X}$-ray $(\lambda=1.540598 \AA$ ) obtained with an incident-beam germanium monochromator. The characteristics of this arrangement and its instrument resolution function have been described by Loüer and Langford [19]. Table I summarises the scanning conditions used to obtain the diffraction patterns.

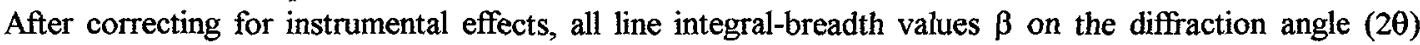
scale are converted to reciprocal units by using the relationship:

$$
\beta_{f}^{*}=\frac{\beta \cos \theta}{\lambda}
$$
where $\lambda$ is the wavelength.

In order to analyse the microstructure, we must examine the line breadths using the Williamson-Hall plot [20], eg the variation of $\beta_{f}^{*}$ as a function of $d^{*}=\frac{2 \sin \theta}{\lambda}$. This plot gives an overview of the nature of the broadening due to sample imperfections. In the case of a linear plot, the slope s gives an indication of the microstrains and the intercept inverse $1 / \beta_{\mathrm{fo}}$, a measure of an average crystallite size. Non-zero $s$ and $1 / \beta_{\mathrm{fo}}$ indicate that both microstrain and size effect contribute to the line broadening [18].

\section{RESULTS}

\subsection{Conductivity vs annealing time behavior}

The conductivity-annealing time at $600^{\circ} \mathrm{C}$ behavior of the 3 types of film is shown in Figure 1 . It is normalized to the saturation value.

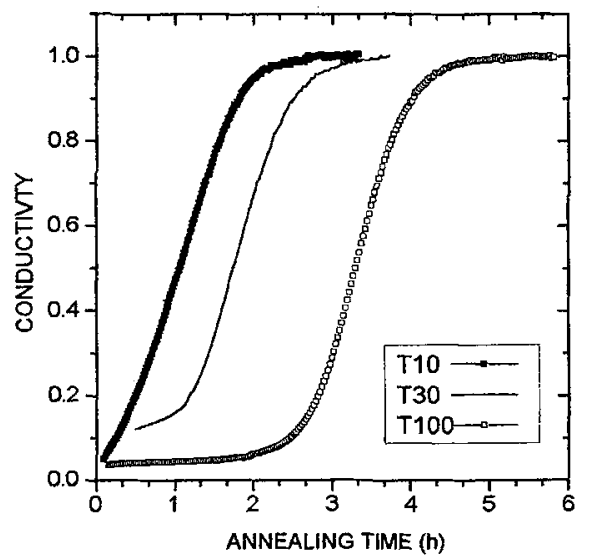

Figure 1: Conductivity of the 3 types of films at $600^{\circ} \mathrm{C}$ vs annealing time normalized to the saturation value

Such behavior was previously obtained by Bisario et al. [21]. At begining, the conductivity slightly increases or is nearly constant. This corresponds to the nucleation process which takes place at the substrate-film interface. The conductivity then abruptly increases and saturates. The high increase was attributed [21] to the crystalline growth perpendicularly to the interface.

Taking into account this explanation, we can see in Fig. 1 an increase of the nucleation time $t_{n}$, defined as the time before the conductivity rises, with the deposition rate. The conductivity saturates after an annealing of $2 \mathrm{~h}$ for T10 type films and $4 \mathrm{~h}$ for T100 one. Thus the T10 films crystallize more quickly.

\subsection{Conductivity vs temperature characteristic at different annealing times}

The conductivity of T10 type film as a function of the temperature in Arrhenius plots is presented in Fig. 2.A. The conductivity of T10-0 and T10-1 films slowly decreases at low temperatures. 

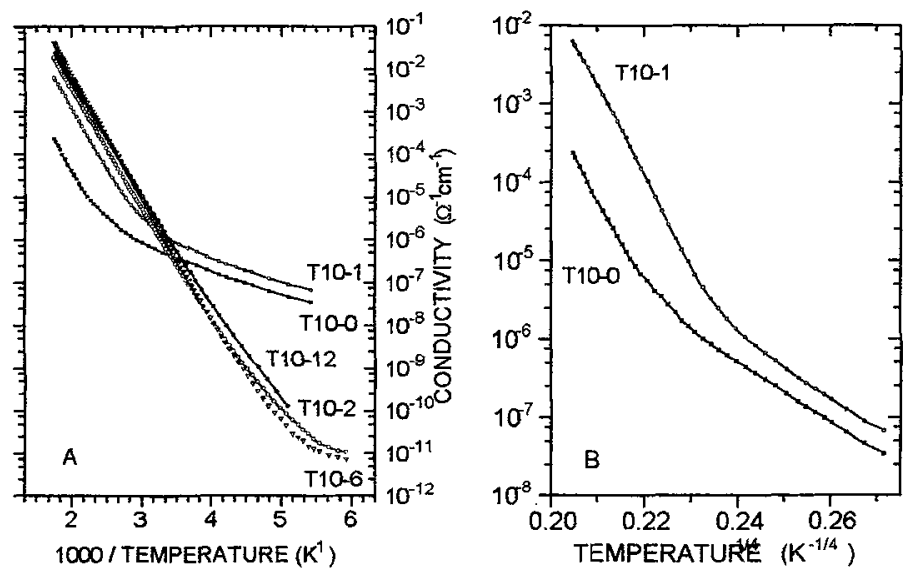

Figure 2: Conductivity of the T10 type films at different annealing times at $600^{\circ} \mathrm{C}(\mathrm{A})$ and hopping conduction in unannealed (T10-0) and ih annealed (T10-01) films at low temperatures (B).

The logarithm of the conductivity of these films is proportionnal to $\mathrm{T}^{-1 / 4}$ for these low temperatures as shown in Fig. 2.B. This temperature dependence can be interpreted in terms of a variable range hopping conduction mechanism [22]. Figure 2.B shows that the hopping conduction takes place at lower temperature in T10-1 film than in T10-0 one. This shift is an indication of a microstructural variation. The hopping conductivity can be fitted by the relation :

$$
\sigma=\sigma_{0} \exp \left(-\frac{T_{0}}{T}\right)^{3 / 4}
$$

The density of states at Fermi level $N\left(E_{F}\right)$ is then given by :

$$
\mathrm{N}\left(\mathrm{E}_{\mathrm{F}}\right)=\frac{18 \alpha^{3}}{\mathrm{k} \mathrm{T}_{0}}
$$

where $\alpha$ is the exponential decay rate of the localized states.

\begin{tabular}{|c|c|c|c|}
\cline { 2 - 4 } \multicolumn{1}{c|}{} & $\mathrm{T} 10-0$ & $\mathrm{~T} 30-0$ & $\mathrm{~T} 100-0$ \\
\hline $\begin{array}{c}\mathrm{N}\left(\mathrm{E}_{\mathrm{F}}\right) \\
\left(\mathrm{cm}^{-3} \mathrm{eV}^{-1}\right)\end{array}$ & $2.10^{19}$ & $1.510^{19}$ & $1.10^{19}$ \\
\hline
\end{tabular}

Table II: Density of states at Fermi level $N\left(E_{F}\right)$ for the 3 unannealed film types calculated using $\alpha=5 \AA^{-1}$

\begin{tabular}{|c|c|c|c|}
\cline { 2 - 4 } \multicolumn{1}{c|}{} & $\mathrm{T} 10-0$ & $\mathrm{~T} 30-0$ & $\mathrm{~T} 100-0$ \\
\hline $\begin{array}{c}\mathrm{E}_{\mathrm{a}} \\
(\mathrm{eV})\end{array}$ & 0.61 & 0.65 & 0.73 \\
\hline
\end{tabular}

Table III: Activation energy $\mathrm{E}_{\mathrm{a}}$ of the conductivity in high temperature range

Table II shows that $\mathrm{N}\left(\mathrm{E}_{\mathrm{F}}\right)$ decreases when the deposition rate increases; this indicates a trend to a decrease of the dangling bonds content.

At high temperatures, all curves are thermally activated with an energy decreasing when the annealing time increases. Activation energy $E_{a}$ for as-deposited films is shown in Table III. The increase of $E_{a}$ with deposition rate indicates a trend to a stable amorphous structure as usually defined [23]. More important is the high value of $E_{a}$ obtained for T100-0 film and characteristic of a relaxed amorphous silicon network. T10-2 is lightly curved at low temperatures, T10-6 and T10-12 curves are however linear in the whole temperature range ( 200 to $570 \mathrm{~K}$ ). This last behavior indicates a very negligible contribution of an hopping conduction even at low temperatures. From this point of view, T10-6 and T10-12 may be then considered as fully cristallized.

\subsection{Optical Transmission}

The absorption coefficient $\alpha$ of T100 type film as a function of photon energy at different annealing times is shown in Fig. $3 \mathrm{~A}$. A sudden decrease of $\alpha$ is observed in the strong absorption regime when the annealing time exceeds $2 \mathrm{~h}$. In this regime, a Tauc plot (Fig.3B) shows a gap of $1.55 \mathrm{eV}$ for T100-0. 

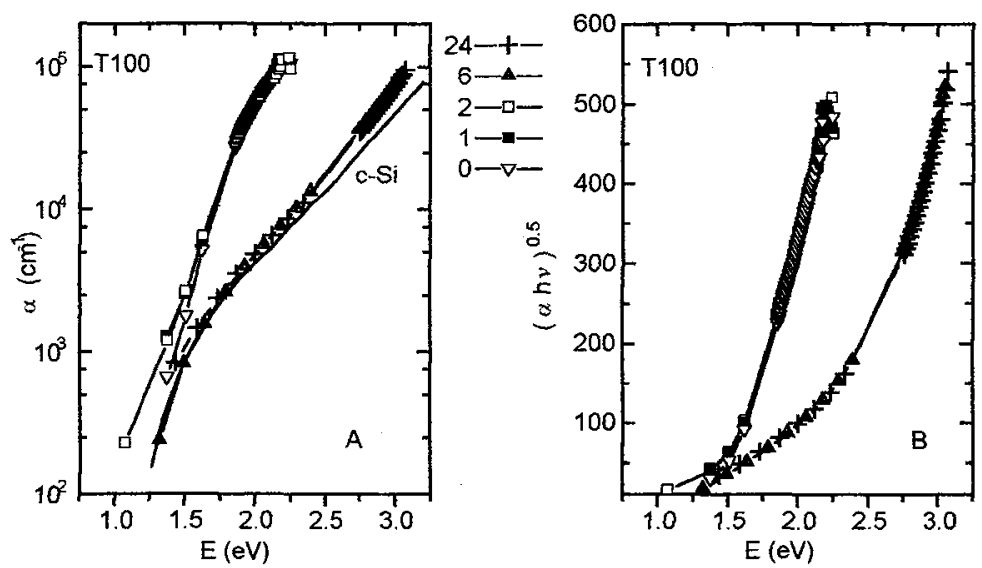

Figure 3 : Absorption coefficient (A) and Tauc plots (B) for T100 type films. Absorption of cristalline silicon (c-Si - ) [25] is shown in (A) for comparison

The same absorption behavior is observed in the other types of films. The absorption coefficient $\alpha$ for unannealed films increases, however, with the deposition rate.

These behaviors are typical of amorphous-polycrystalline phase transition [24]. Moreover the unannealed films show an optical absorption characteristic of an amorphous silicon: $\alpha$ at $2 \mathrm{eV}$ greater than $10^{4} \mathrm{~cm}^{-1}$ and a Tauc gap value around $1.55 \mathrm{eV}$.

The determination of an exact value for the Tauc gap is known to be difficult specially when the valence and conduction band tails extend deeply in the gap. An estimation of the Urbach tail in our unannealed samples gives a high value around $120 \mathrm{meV}$. Hence we define the gap $\mathrm{E}_{5.4}$ as the photon energy at $\alpha=5.10^{4}$ $\mathrm{cm}^{-1}$, which corresponds more likely to the distance between the valence and conduction bands than the Tauc gap. Gaps $\mathrm{E}_{5.4}$ of our different films are reported in Table IV together with that of crystalline silicon [25].

\begin{tabular}{|c|c|c|c|c|c|c|c|c|}
\hline $\begin{array}{c}\text { Type of } \\
\text { film Tn }\end{array}$ & Tn-0 & Tn-1 & Tn-2 & Tn-3 & Tn-6 & Tn-12 & Tn-24 & c-Si \\
\hline T10 & 2.03 & 2.14 & 2.75 & 2.815 & 2.83 & 2.835 & 2.84 & 3 \\
\hline T30 & 2.00 & 2.01 & 2.10 & 2.74 & 2.80 & 2.835 & 2.845 & 3 \\
\hline T100 & 1.995 & 1.98 & 1.97 & & 2.86 & 2.87 & 2.88 & 3 \\
\hline
\end{tabular}

Table IV: Photon energy $E_{5.4}$ for $\alpha=5.10^{4} \mathrm{~cm}^{-1}$.

We observe an upward trend toward the crystalline silicon gap. The final values are very close to the c-Si one and closer as the depostion rate increases.

The gap of T100 films decreases before rising towards the c-Si one. This decrease may be due to an exodiffusion of hydrogen from the T100 film. This means that some hydrogen may be present in unannealed T100 film. Such hypothesis is not surprising. Hence exodiffision of hydrogen from silicon occurs generally around $600^{\circ} \mathrm{C}$ and even at higher temperatures depending on the microstructure of the material [26].

Moreover infrared transmission measurements on $\mathrm{T} 10-0, \mathrm{~T} 30-0$ and $\mathrm{T} 100-0$ show the presence of very weak absorption around $2000-2100 \mathrm{~cm}^{-1}$ in T30-0 and T100-0 spectra. This absorption is characteristic of $\mathrm{Si}-\mathrm{H}$ bonds. The very weak absorption does not allow us to estimate an hydrogen content. Qualitatively, we can see however a higher absorption from T100-0 than T30-0. On the other hand, we have seen a decreased density of states at Fermi level when the deposition rate increases.

All these observations and remarks are consistent with the presence of hydrogen in our unannealed films. The hydrogen content higher in T100-0 than in T30-0 and not detectable in T10-0 may explain the different cristallization times observed. With exodiffusion of hydrogen, more dangling bonds are created. According to Germain et al. [27], dangling bonds must be involved in the crystal growth mechanism. Hence, from this point of view, crystallization appears to be a consequence of bond breaking. 


\subsection{Ellipsometry analysis}
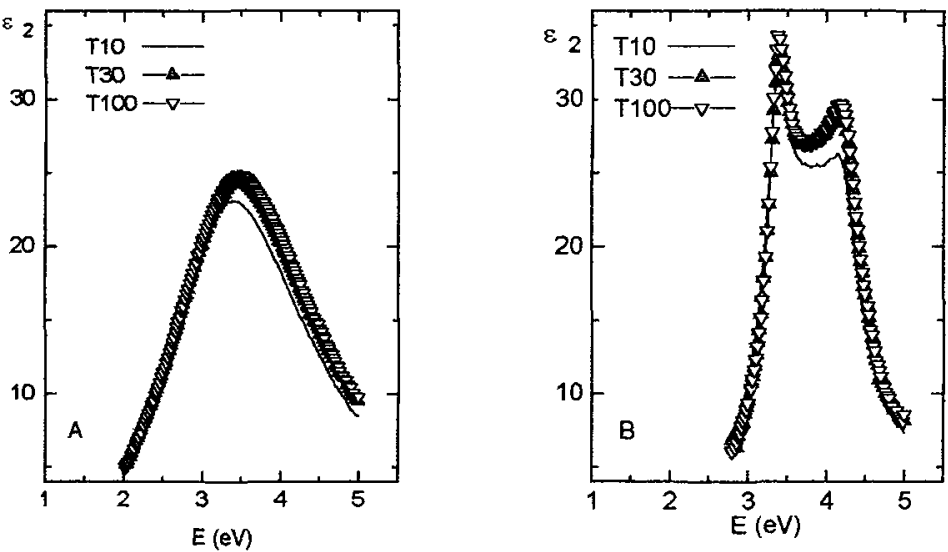

Figure 4: Imaginary part of the pseudo-dielectric function of the 3 types of film in the as-deposited (A) and crystallized (B) states.

The $\varepsilon_{2}$ behavior of as-deposited T10-0, T30-0 and T100-0 films (A) is characteristic of amorphous structure with only one maximum at $3.55 \mathrm{eV}$. The spectra of crystallized T10-12, T30-12, T100-12 films (B) present two maxima at 3.4 and $4.2 \mathrm{eV}$ characteristic of crystalline silicon.

Using BEMA analysis, crystallized films can be described by two layers, the thicker one consisting of a mixed structure (crystalline $\mathrm{Si}$, amorphous $\mathrm{Si}$ and voids), and a thin surface layer consisting of native oxide $\mathrm{SiO}_{2}$. Table $\mathrm{V}$ summarizes the results for these 3 crystallized films.

\begin{tabular}{|c|c|c|c|c|c|}
\hline & \multicolumn{4}{|c|}{ Bulk } & Native Oxide \\
\hline & $\begin{array}{c}\text { Thickness } \\
\check{A} \\
\end{array}$ & $\begin{array}{c}\mathrm{c}-\mathrm{Si} \\
\%\end{array}$ & $\begin{array}{c}\text { a-Si } \\
\%\end{array}$ & $\begin{array}{c}\text { voids } \\
\%\end{array}$ & $\begin{array}{c}\text { Thickness } \\
\stackrel{\Perp}{A}\end{array}$ \\
\hline T10-12 & 8460 & 85 & 10.8 & 4 & 26 \\
\hline T30-12 & 6420 & 90 & 6 & 4 & 17 \\
\hline T100-12 & 9370 & 94 & 3.5 & 2 & 25 \\
\hline
\end{tabular}

Table V: Ellipsometry analysis for the 3 types of film

The amorphous and voids contents decrease when the deposition rate (or pressure) increases. It then appears that the T100 film is « better » crystallized.

\subsection{X - Ray Diffraction}

The X - Ray diffraction pattern of the as-deposited films does not show any lines which may be considered as due to an amorphous phase. An increase of all line intensities when the annealing time increases, is observed in the patterns of annealed films. Moreover, all line areas increase and saturate simultaneously.

Figure 5.A shows Williamson - Hall plots for the T30 films. All plots are linear. A non-zero slope indicates a measurable microstrain effect. Moreover the points do not display a significant scatter, so the microstrains do not depend on the crystallite orientation.

Furthermore, the intercepts $\beta_{\text {fo }}$ are the same and nearly zero for all samples. Hence, no measurable size effect is observed. The crystallite size is greater than the detection limit of X-ray diffraction $(\sim 2000 \AA)$.

Williamson -Hall plots are reported in figure 5.B for fully crystallized films T10-24, T30-24 and T100-24. The same trends as before are observed. It seems that microstrain effects are the same whatever the deposition pressure is. The size effect is again negligible. A trend to a decrease of the intercept $\beta_{f v}$ induced by an increase of the crystallite size, from T10 to T100 types of film, is however detectable. 

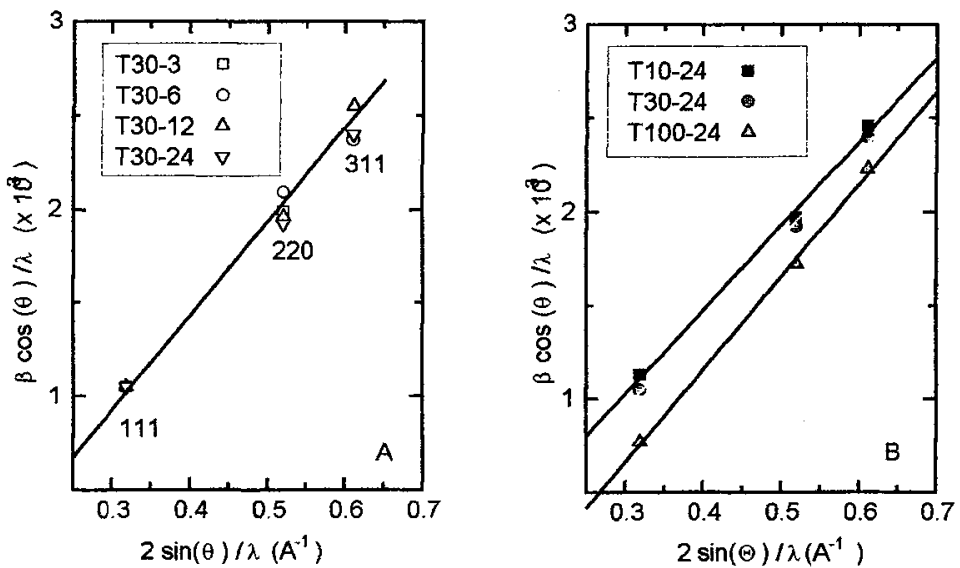

Figure 5: Williamson - Hall plots for T30 type of films at different annealing times (A) and for the 3 types of films annealed during 24 hours $(B)$.

\section{DISCUSSION AND CONCLUSION}

Our work shows that the silicon films, deposited by $\mathrm{LPCVD}$ at $550^{\circ} \mathrm{C}$ and with a pressure greater than 10 $\mathrm{Pa}$ using pure silane, are amorphous. The numerous characterization techniques used give evidence of the amorphous character of these as-deposited films. Hence, we can assert that spontaneous crystallization does not occur during the deposition.

The nucleation time is however different from one type of films to another, due to the amorphous microstructure. Films deposited at high rate correspond more likely to the relaxed amorphous network. The quality of the polysilicon produced by annealing these high deposition rate films at $600^{\circ} \mathrm{C}$ is largely enhanced. Particularly it is densely packed ( negligible voids content) with a very low degree of amorphization. Its absorption is very close to that of crystalline silicon c-Si (Fig. 3). The photon energies for an absorption coefficient of $510^{4} \mathrm{~cm}^{-1}$ are respectively 2.88 and $3 \mathrm{eV}$ for the high deposition rate film and for c-Si. Comparatively this energy is $2.6 \mathrm{eV}$ for polysilicon, deposited amorphous by PECVD and crystallized [3].

The crystallization time, defined from the in-situ conductivity measurements at $600^{\circ} \mathrm{C}$, is about $4 \mathrm{~h}$ for the high deposition rate amorphous film. Such a short time is very attractive in the attempt to obtain simultaneously « acceptable » crystallization time and high quality polysilicon. This assertion is emphasized if we consider the total time $t$ of the process : deposition time $t_{d}$ and crystallization time $t_{a}$ (Table VI).

\begin{tabular}{|c|c|c|c|}
\cline { 2 - 4 } \multicolumn{1}{c|}{} & $\mathrm{t}_{\mathrm{d}}$ & $\mathrm{t}_{\mathrm{a}}$ & $\mathrm{t}$ \\
\hline $\mathrm{T} 10$ & $13 \mathrm{~h}$ & $2 \mathrm{~h}$ & $15 \mathrm{~h}$ \\
\hline $\mathrm{T} 30$ & $7 \mathrm{~h} 30 \mathrm{~min}$ & $2 \mathrm{~h} \mathrm{30min}$ & $10 \mathrm{~h}$ \\
\hline T100 & $3 \mathrm{~h} \mathrm{30min}$ & $4 \mathrm{~h}$ & $7 \mathrm{~h} \mathrm{30min}$ \\
\hline
\end{tabular}

Table VI: Deposition time $t_{d}$ at $550^{\circ} \mathrm{C}$, annealing time $t_{a}$ at $600^{\circ} \mathrm{C}$ and total process time $t$ for a $1 \mu \mathrm{m}$ thick film deposited in $\mathrm{T} 10, \mathrm{~T} 30$ and $\mathrm{T} 100$ conditions

The process time for the best quality polysilicon (T100) is then half of the T10 one.

In conclusion, using the standard deposition and annealing conditions $\left(\mathrm{T}_{\mathrm{d}}=550^{\circ} \mathrm{C}\right.$ and $\left.\mathrm{T}_{\mathrm{a}}=600^{\circ} \mathrm{C}\right)$ in conventional LPCVD, we obtained a high quality polysilicon compatible with a low process time. In this way, further attempts to improve polysilicon quality by a decrease of the process temperature may be of reduced interest. 
We have shown, however, that microstrains exist inside coherently diffracting domains. Further improvements may consist of an additional annealing (such as rapid thermal annealing) compatible with the need of low substrate temperature.

\section{Acknowledgments}

The authors are grateful to D. Louer (Université Rennes I) for performing X-ray diffraction measurements and for useful discussions.

\section{References}

[1] Mimura A., Konishi N., Ono K., Hosokawa Y., Ono Y.A., Suzuki T., Miyata K. and Kawakami H., IEEE ED50 (1989) 351

[2] Harbeke G., Krausbauer L., Steigmeier E.F., Widmer A.E., Kappert H.F. and Neugebauer G., Appl. Phys. Lett. 42 (1983) 249

[3] Dyer T.E., Marshall J.M. and Davies J.F., Phil. Mag. B69 (1994) 509

[4] Hatalis M.K. and Greve D., J. Appl. Phys. 63 (1988) 2260

[5] Hadji L., Joubert P., Gendouz M., Duhamel N. and Loisel B., Mat. Res. Symp. Proc. 230 (1992) 177

[6] Scheid E., De Mauduit B., Taurines P. and Bielle-Daspet D., Jpn. J. Appl. Phys. 29 (1990) L2105

[7] Voutsas A.T. and Hatalis M.K.; J. Appl. Phys. 76 (1994) 777

[8] Matsuyama T., Wakissada K., Kameda M., Tanaka M., Matsuoka T., Tsuda S., Nakano S., Kishi Y. and Kuwano Y., Jap. J. Appl. Phys. 29 (1990) 2327

[9] Meaudre R., Meaudre M., Vignoli S., Roca i Cabarrocas P., Bouizem Y. and Theye M.L., Phil. Mag. B67 (1993) 497

[10] Bisaro R., Magariño J., Pastol Y., Germain P. and Zellama K., Phys. Rev. B40 (1989) 7655

[11] Paul W., Lewis A.J., Connel G.A.N. and Moustakas T.D., Solid State Comm. 20 (1976) 969

[12] Mohammed-Brahim T., Rahal A., Ababou N., Beldi N., Aoucher M., Mencaraglia D., Djebbour Z., Sib J., Kleider J.P. and C.Longeaud, 10th European Photovoltaic Solar Energy Conference (EPSEC) Lisbon (1991)

[13] Cuniot M., Dixmier J., Elkaim P., Bardet E. and Bourée J.E., 12th EPSEC Amsterdam (1994)

[14] Jones S.J., Chen Y., Williamson D.L., Kroll U. and Roca i Cabarrocas P., J. Non Cryst. Solids 164$166(1993) 131$

[15] Collins R.W., in Advanced in Disordered Semiconductors I (1989) 1003 ed. Fritsche World Scientific Singapore

[16] Bisaro R., Magariño J., Proust N. and Zellama K., J. Appl. Phys. 59 (1986) 1167

[17] Swanepoel R., J. Phys. E16 (1983) 1214[26]

[18] Langford J.I. (1992) pp. 110-26 Accuracy in Powder Diffraction II ed. Prince E. and Stalick J.K., National Institute for Science and Technology, Gaithersburg, MD.

[19] Loüer D. and Langford J.I., J. Appl. Crystallogr. 21 (1987) 430

[20] Williamson J.K. and Hall W.H., Acta Metall. 1 (1953) 22

[21] Bisaro R., Magariño J., Zellama K., Squelard S., Germain P. and Morhange J.F., Phys. Rev. B31 (1985) 3568

[22] Mott N.F., Phil. Mag. 19 (1969) 835

[23] Theye M.L. in Optical Properties of Solids. (1976) ed. Seraphin B.O. North Holland Amsterdam

[24] Janai M., Allred D.D., Booth D.C. and Seraphin B.O., Solar Energy Materials 1 (1979) 11

[25] Dash W.C. and Newman R., Phys. Rev. 99 (1955) 1151

[26] Roca i Cabarrocas P., Djebbour Z., Kleider J.P., C.Longeaud, Mencaraglia D., Sib J., Bouizem Y., Theye M.L., Sardin G. and Stoquert J.P., J. Phys. France 2 (1992) 1979

[27] Germain P.J., Paesler M.A., Zellama K. in Cohesive Properties of Semiconductors under Laser Irradiation E69 (1983) 506 NATO Advanced Study Institute Series ed. Laude L.D. Nijhoff, The Hague 